\title{
Salvage of a TRAM breast reconstruction flap using the retrograde internal mammary artery system
}

\author{
Sameena Hassan, Tuabin Rasheed, Anna Raurell \\ Department of Plastic and Reconstructive Surgery, Nottingham University Hospitals NHS Trust, United Kingdom
}

Address for correspondence: Dr. Sameena Hassan, Department of Plastic and Reconstructive Surgery, Nottingham University Hospitals, NHS Trust City Campus Hucknall Road, NG5 1PB, United Kingdom. E-mail: s.hassan@nhs.net

\section{ABSTRACT}

Background: Free tissue transfer provides an optimal means for breast reconstruction in creating an aesthetically natural appearance that is durable over time. The choice of donor vessels vary from surgeon to surgeon, but the internal mammary axis is one of the most popular choices together with the thoracodorsal vessels. Aims and Results: We present the case of a salvaged free transverse rectus abdominis myocutaneous breast reconstruction in which end-to-end antegrade anastomosis to the internal mammary artery (IMA) was not possible due to frail vessel walls, but retrograde anastomosis to the IMA and antegrade anastomosis of internal mammary vessel resulted in a perfused and viable flap. Conclusion: We suggest the use of the retrograde internal mammary arterial system for microsurgical anastomosis when the anterograde flow is not adequate, the vessel wall is friable, and when other more common options are not available.

\section{KEY WORDS}

Breast reconstruction; deep inferior epigastric perforator; retrograde

\section{INTRODUCTION}

utologous flaps provide an optimal means for breast reconstruction in creating an aesthetically natural appearance that is durable over time. The internal mammary vein and artery are one of the choices of recipient vessels. In some patients, the vessels on the left side of the chest are smaller, in cases of radiotherapy they can be more friable, and sometimes scarring due to previous surgery can influence the quality of the vessels. Other choices for recipient vessels are most commonly

\begin{tabular}{|l|l|}
\hline \multicolumn{2}{|c|}{ Access this article online } \\
\hline Quick Response Code: & Website: \\
\hline & www.ijps.org \\
\cline { 2 - 2 } & Dol: \\
\hline & $10.4103 / 0970-0358.146657$ \\
\hline
\end{tabular}

the thoracodorsal axis, although use of thoracoacromial vessels as recipient vessels has been described. ${ }^{[1]}$ Salvage techniques using the retrograde limb of the internal mammary vessels have been described following flap compromise of the original antegrade anastomosis..$^{[2,3]}$

We present the case of a salvaged free transverse rectus abdominis myocutanoeus flap breast reconstruction in which end-to-end antegrade anastomosis to the internal mammary artery was not possible due to frail vessel walls but retrograde anastomosis to the internal mammary artery (IMA), and antegrade anastomosis of internal mammary vein resulted in a perfused and viable flap. We suggest considering the possible use of the retrograde internal mammary system for microsurgical anastomosis when the anterograde flow is not adequate and when other more common options are not available. 


\section{CASE REPORT}

A 52-year-old female ex-smoker was admitted for elective left delayed breast reconstruction with a free tissue transfer. She had previously undergone a left mastectomy with axillary node sampling and adjuvant chemotherapy for a multifocal invasive grade two lobular breast cancer with a Nottingham prognostic indicator of 3.64. The tumour excision was complete with no histological evidence of vascular invasion nor was there tumour evident on any of the four nodes sampled. It was weakly estrogen receptor positive and strongly progesterone receptor positive but human epidermal growth factor receptor- 2 negative. As this is not a typical feature of lobular carcinoma, the patient received six cycles of adjuvant chemotherapy to reduce her risk of disease recurrence in addition to hormonal treatment with anastrozole. Her past medical history included familial hypercholesterolaemia and transient ischaemic attack for which she was anticoagulated with aspirin, discontinued 10 days prior to surgery.

The transverse rectus abdominis myocutaneous flap was raised on the left deep inferior epigastric vessels. The IMA and vein were exposed at the level of the $3^{\text {rd }}$ intercostal space without dissection of the costal cartilage rib exposing a good calibre size on each vessel. The internal mammary vessels were divided, and the proximal end of each used as the recipient vessel to establish antegrade flow. Of note, the arterial vessel wall was thin, and there was also some bruising in the adventitia. End-to-end anastomosis was carried out as a routine with a 9-0-nylon suture. The IMA wall was found to be extremely friable and kept tearing. Proximal costal cartilage was removed to get more exposure and length. However the vessel adventitia was damaged and the wall was very thin at this level as well. A further three attempts at anastomosis did not result in a successful flow. The proximal IMA was shortened and a further attempt at anastomosis undertaken; however, the adventitia was again found to be soft and easily friable. The thoracodorsal axis was explored including the serratus branch of the thoracodorsal artery, the thoraco-acromial and lateral thoracic artery. Unfortunately, the vessels were of small calibre, and the flow was deemed unsuitable to support a free flap.

In a last attempt to salvage the flap, we considered the distal end of the IMA, as the wall appeared to be in a better condition, and the retrograde flow seemed as good as the anterograde flow. End-to-end anastomosis of the distal part of the divided IMA was successful on the first attempt, establishing retrograde flow with anterograde flow of the venous anastomosis. The total ischaemic time in this case was $3 \mathrm{~h}$. The patient experienced an unremarkable post-operative recovery and was discharged home on the third post-operative day. At 3 months post-operative the patient was satisfied with the aesthetic appearance of the breast reconstruction, which was well perfused with no areas of skin necrosis.

\section{DISCUSSION}

Several case reports have advocated the use of retrograde flow in patients undergoing dual pedicled flaps in maximising the amount of vascularised tissue that can be safely transferred. ${ }^{[4,5]}$ Patency of the retrograde internal mammary vein anastomosis has been described on 15 patients undergoing deep inferior epigastric perforator flap reconstruction using indocyanine green angiography, without flap failure or congestion. ${ }^{[6]}$ Exclusive use of retrograde internal mammary vein as a source of venous drainage is unadvisable, due to the presence of valves in a proportion of internal mammary veins at the level of the $2^{\text {nd }}$ and $3^{\text {rd }}$ intercostal space. ${ }^{\text {[7] }}$ Flow velocities in the retrograde internal mammary vein are less than those in the antegrade internal mammary vein, but these are not statistically significant and probably attributable to the smaller calibre of the recipient vessel. ${ }^{[8]}$ By comparison, mean arterial pressure in antegrade IMA is significantly greater than in retrograde flow. ${ }^{[9]}$ In human studies, with patients undergoing transverse rectus abdominis myocuataneous reconstruction, pressures in the distal IMA were 75-77\% of the pressure measured at the proximal end, but still sufficient to allow flap perfusion. ${ }^{[10]}$

The arterial inflow and venous outflow of the distal internal mammary vessels are supplied by terminal branches including superior epigastric, musculophrenic, intercostals, and communicating branches. Patients must be ideally suited to retrograde anastomosis to the distal limb, excluding those with mechanical injury to the superior epigastric vessels or those with previous intercostal artery perforator flaps. Use of the retrograde internal mammary system for breast reconstruction prohibits its use in cardiac surgery. When these factors are not present, we advocate the use of the retrograde IMA system to vascularise free tissue transfer in cases where it is not technically possible to use the antegrade IMA system. 


\section{REFERENCES}

1. Chun JK, Harmaty M, Ting J. Thoracoacromial vessels as the recipients for supercharged muscle-sparing transverse rectus abdominis myocutaneous flaps. J Reconstr Microsurg 2007;23:125-9.

2. Caulfield RH, Maleki-Tabrizi A, Mathur B, Ramakrishnan V. Salvage of a DIEP flap using a retrograde flow anastomosis. J Plast Reconstr Aesthet Surg 2008;61:346-7.

3. Liu TS, Ashjian P, Festekjian J. Salvage of congested deep inferior epigastric perforator flap with a reverse flow venous anastomosis. Ann Plast Surg 2007;59:214-7.

4. Chan RK, Przylecki W, Guo L, Caterson SA. Case report. The use of both antegrade and retrograde internal mammary vessels in a folded, stacked deep inferior epigastric artery perforator flap. Eplasty 2010;10:e32.

5. Agarwal JP, Gottlieb LJ. Double pedicle deep inferior epigastric perforator/muscle-sparing TRAM flaps for unilateral breast reconstruction. Ann Plast Surg 2007;58:359-63.

6. Mohebali J, Gottlieb LJ, Agarwal JP. Further validation for use of the retrograde limb of the internal mammary vein in deep inferior epigastric perforator flap breast reconstruction using laser- assisted indocyanine green angiography. J Reconstr Microsurg 2010;26:131-5.

7. Mackey SP, Ramsey KW. Exploring the myth of the valveless internal mammary vein - A cadaveric study. J Plast Reconstr Aesthet Surg 2011;64:1174-9.

8. Venturi ML, Poh MM, Chevray PM, Hanasono MM. Comparison of flow rates in the antegrade and retrograde internal mammary vein for free flap breast reconstruction. Microsurgery 2011;31:596-602.

9. González-Santos JM, Bastida E, Riesgo M, Vallejo JL, Albertos JV, Fortuny R, et al. Flow capacity of the human retrograde internal mammary artery: Surgical considerations. Ann Thorac Surg 1990;50:360-6.

10. Li S, Mu L, Li Y, Xu J, Yang M, Zhao Z, et al. Breast reconstruction with the free bipedicled inferior TRAM flap by anastomosis to the proximal and distal ends of the internal mammary vessels. J Reconstr Microsurg 2002;18:161-8.

How to cite this article: Hassan S, Rasheed T, Raurell A. Salvage of a TRAM breast reconstruction flap using the retrograde internal mammary artery system. Indian J Plast Surg 2014;47:447-9.

Source of Support: Nil, Conflict of Interest: None declared. 